\title{
Emerging Techniques in Vegetable Oil Analysis Using Stable Isotope Ratio Mass Spectrometry
}

\author{
By Simon D Kelly ${ }^{1}$ and Christopher Rhodes ${ }^{2}$ \\ ${ }^{1}$ The School of Environmental Sciences, University of East Anglia, Norwich, NR4 7TJ, UK \\ E-mail: s.kelly@uea.ac.uk, Fax: +44(0)1603 592679, Tel: +44(0)1603 507719 \\ ${ }^{2}$ Department for Environment, Food and Rural Affairs, Central Science Laboratory, \\ Sand Hutton, York, YO41 1LZ, UK \\ E-mail: c.rhodes@csl.gov.uk, Fax: +44 (0)1904 462133, Tel: +44 (0)1904 462000
}

\section{CONTENTS}

1. Introduction.

2. Description of the instrumentation for stable isotope ratio mass spectrometry.

2.1. Authenticity of maize oil.

3. ${ }^{13} \mathrm{C}$ Compound-specific isotope analysis $\left({ }^{13} \mathrm{C} \mathrm{CSIA}\right)$.

4. ${ }^{13} \mathrm{C}$ Position specific isotope analysis $\left({ }^{13} \mathrm{C}\right.$ PSIA).

5. ${ }^{18} \mathrm{O}$ and ${ }^{2} \mathrm{H}$ pyrolysis CF-IRMS and possibilities for botanical and geographical origin assignment References.

\section{RESUMEN}

Uso de la espectrometría de masas de relaciones isotópicas como técnica emergente en el análisis de aceites vegetales.

A medida que la práctica de la adulteración de aceites vegetales se hace más sofisticada, las posibilidades de evitar la detección utilizando técnicas tradicionales como la cromatografía de gases en columna capilar aumentan. Una de las técnicas más poderosas que más se utilizan en los estudios de autentificación de alimentos es la espectrometría de masas de relaciones isotópicas, que utiliza diferencias en la abundancia natural de isótopos estables de elementos ligeros biológicos hidrógeno, nitrógeno, carbón, oxigeno y azufre para detectar fraude en los alimentos. La espectrometría de masas de relaciones isotópicas ha encontrado aplicación en la autentificación de una amplia gama de alimentos, incluyendo zumos de frutas, vinos, bebidas alcohólicas de alta graduación, miel, y en la detección de la adulteración de los compuestos aromáticos con sus análogos de origen sintético. Este trabajo revisa el estado actual de los conocimientos de autentificación de aceites vegetales utilizando la espectrometría de masas de relaciones isotópicas y las aportaciones de tecnologías emergentes tales como la espectrometría de masas de compuestos isotópicos. Estos últimos desarrollos ofrecen la posibilidad de suministrar una detección más rápida y mejorada de la adulteración de aceites vegetales.

PALABRAS-CLAVE: Aceite vegetal - Análisis - Espectrometría de masas de relaciones isotópicas.

\section{SUMMARY}

Emerging techniques in vegetable oil analysis using stable isotope ratio mass spectrometry.

As the practice of vegetable oil adulteration becomes more sophisticated, the possibility to subvert detection using established techniques such as capillary gas chromatography is increasing. One of the most powerful techniques to be used in food authenticity studies is stable isotope ratio mass spectrometry (SIRMS) which utilises differences in the natural abundance of the stable isotopes of the 'light' bio-elements hydrogen, nitrogen, carbon, oxygen and sulfur to detect food fraud. SIRMS has found application in the authentication of a wide range of foodstuffs, including fruit juices, wines, spirits, honey and to detect the adulteration of flavour compounds with synthetic analogues. This papers reviews the current state-of-the-art for the authentication of vegetable oils using SIRMS and highlights emergent techniques such as compound- and position specific-isotope mass spectrometry. These latter developments offer the potential to provide more rapid and improved detection of the economic adulteration of vegetable oils.

KEY-WORDS: Analysis - Stable isotope ratio mass spectrometry - Vegetable oil.

\section{INTRODUCTION}

It is important to be able to detect vegetable oil adulteration since it can constitute a major economic fraud and may have serious implications for public health (Firestone and Reina 1996). A variety of physical and chemical tests have been developed for determination of the authenticity of oils. The purity of many oils can be established from conventional chemical analyses such as fatty acid and triglyceride compositions, sterol concentrations and tocopherol contents. These tests have been complemented and in some cases superseded by newer instrumental techniques such as nuclear magnetic resonance spectroscopy and mass spectrometry (Goodacre et al. 1993).

Food analysis has improved dramatically and the more overt types of adulteration or mislabelling are now unlikely to escape detection. However, more subtle practices emerge as unscrupulous producers seek to increase their profits. One of the most powerful techniques to be used in food authenticity studies is stable isotope ratio mass spectrometry (SIRMS). SIRMS has found application in the authentication of a wide range of foodstuffs, especially for the detection of added cane sugar in fruit juices (Bricout and Koziet 1987), wines (Dunbar and Schmidt 1984), spirits (Parker et al. 1998), honey (White et al. 1998) and to detect the adulteration of flavour compounds with synthetic analogues (Culp and Noakes 1990). The majority of the reported research has focused on bulk or global stable carbon isotope ratios $\left({ }^{13} \mathrm{C} /{ }^{12} \mathrm{C}\right)$. However, in 
the second part of this monograph the potential of compound-specific and position-specific carbon isotope ratios, and the application of hydrogen $\left({ }^{2} \mathrm{H} /{ }^{1} \mathrm{H}\right)$ and oxygen $\left({ }^{18} \mathrm{O} /{ }^{16} \mathrm{O}\right)$ isotopic ratios, for the control of vegetable oil authenticity will be discussed.

Approximately $98.89 \%$ of all carbon in nature is ${ }^{12} \mathrm{C}$ and $1.1 \%$ is ${ }^{13} \mathrm{C}$. The amount of ${ }^{13} \mathrm{C}$ present in a sample is expressed as a ratio to the amount of ${ }^{12} \mathrm{C}$ present, relative to an international standard using the $\delta$ notation. This notation has the units per mil (\%o).

$$
\begin{gathered}
\delta{ }^{13} \mathrm{C}=\underset{\text { where } \mathrm{R}={ }^{13} \mathrm{C} /{ }^{12} \mathrm{C}}{\left[\left(\mathrm{R}_{\text {sample }} / \mathrm{R}_{\text {standard }}\right)-1\right] \times 10^{3}} \\
\text { wher }
\end{gathered}
$$

The original international standard was a marine carbonate, Pee Dee Belemnite (PDB) which had an accepted value of $R_{P D B}=0.0112372 \pm 0.0000009$. Supplies of PDB are now exhausted and the current international standard is a carbonate with the designation NBS19. However, for ease of comparison with previous work in this field results are normally presented versus the original primary standard, PDB.

The $\delta^{13} \mathrm{C}$ value of plants varies because of isotopic fractionation during physical, chemical and biological processes. Photosynthetic fixation of $\mathrm{CO}_{2}$ by plants takes place by three different routes, depending on the nature of the plant. Most terrestrial plants photosynthesise using the Calvin or $\mathrm{C}_{3}$ pathway in which $\mathrm{CO}_{2}$ is fixed via the carbon cycle to from a three-carbon compound. Some plants, mainly tropical grasses, such as maize and sugar cane use the Hatch-Slack or $\mathrm{C}_{4}$ pathway in which the initial "Hatch-Slack" step is via a dicarboxylic acid, a four carbon compound. A third photosynthetic class of plants uses the CAM (Crassulacean acid metabolism) pathway. Typical CAM plants are

Table I

$\delta^{13} \mathrm{C}$ values of a range of common edible oils

\begin{tabular}{lc}
\hline \multicolumn{1}{c}{ Sample } & $\delta^{13} \mathrm{C}(\% \circ$, versus PDB $)$ \\
\hline Cocoa Butter & -28.3 \\
Corn (maize) & -15.0 \\
Cottonseed & -27.8 \\
Linseed & -26.2 \\
Olive & -28.7 \\
Palm & -29.6 \\
Peanut & -27.8 \\
Rapeseed & -28.6 \\
Sesame & -27.9 \\
Soyabean & -30.1 \\
Sunflower & -26.0 \\
Wheat germ & -26.0 \\
\hline
\end{tabular}

succulents and are of minor importance in the oleochemical industry.

In the $\mathrm{C}_{3}$ pathway carbon dioxide is fixed via the carboxylation of ribulose-1,5-diphosphate to form phosphoglyceric acid (a 3-carbon molecule). This enzyme catalysed reaction discriminates against ${ }^{13} \mathrm{C}$ and so proceeds with a relatively large isotope effect (O'Leary 1981). This means that less ${ }^{13} \mathrm{CO}_{2}$ is incorporated into $\mathrm{C}_{3}$ plants than into $\mathrm{C}_{4}$ plants. $\mathrm{C}_{3}$ plants have bulk $\delta^{13} \mathrm{C}$ values in the range -24 to $-30 \%$ 。 whereas $\mathrm{C}_{4}$ plants have bulk $\delta^{13} \mathrm{C}$ values from -9 to $-14 \%$. Table I shows typical $\delta{ }^{13} \mathrm{C}$ values for a range of common edible oils.

\section{DESCRIPTION OF THE INSTRUMENTATION FOR STABLE ISOTOPE RATIO MASS SPECTROMETRY}

Stable isotopes have been applied to many areas of biological research including biochemistry, physiology, ecology and agriculture. The ratios of stable istotope such as ${ }^{13} \mathrm{C} /{ }^{12} \mathrm{C},{ }^{15} \mathrm{~N} /{ }^{14} \mathrm{~N},{ }^{18} \mathrm{O} /{ }^{16} \mathrm{O}$ and ${ }^{2} \mathrm{H} /{ }^{1} \mathrm{H}$ give important information regarding many biological processes and transformations. Approaches such as the doubly- labelled water method for the determination of energy expenditure and ${ }^{13} \mathrm{C}$ based breath tests for ulcer diagnosis are used to obtain information that would be difficult or impossible to derive by any other means (Chapman et al. 1990). These tests are all based on conventional dual-inlet high precision gas isotope ratio mass spectrometry the principles of which were developed in the late 1940's (Ehleringer and Rundel 1988). The key features of this instrument are dual variable volume inlets that allow sequential admission of sample and standard to the vacuum system for comparison and a tight electron impact source for sensitive ionization of inert gases. The ions pass through a flight tube and are separated into beams of different masses by a magnetic field. Three masses of interest are then monitored by a series of Faraday cup collectors. The signal is amplified and, for carbon, the relative abundances of the ions at $\mathrm{m} / \mathrm{z} 44,45$ and 46 are determined. The major drawbacks to a dual-inlet instrument are (1) the minimum requirement of about $1 \mathrm{mg}$ of sample or $50-100 \mu \mathrm{g}$ using a cold-finger trap and (2) the instrument will accept only pure $\mathrm{CO}_{2}, \mathrm{H}_{2}$ or $\mathrm{N}_{2}$ which must be prepared from the compound (s) of interest beforehand.

Recently continuous flow gas preparation devices have been developed to interface directly to IRMS instruments. These offer many advantages including smaller sample requirement and greater sample throughput. The continuous flow elemental analyser-IRMS (EA-IRMS) is used to measure the isotope ratio of a particular element in the entire sample. The elemental analyser oxidizes all the 


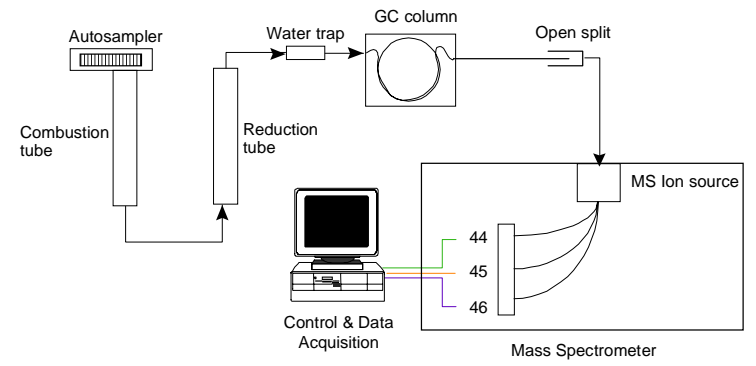

Figure 1

Schematic diagram of an elemental analyser-isotope ratio mass spectrometer (EA-IRMS).

organic compounds present in the sample by flash combustion (Figure 1). Samples are loaded into tin capsules and dropped into a furnace operating at $1000^{\circ} \mathrm{C}$. While in an atmosphere of oxygen the tin ignites and burns exothermically. At this point the temperature rises to about $1800{ }^{\circ} \mathrm{C}$ oxidising the sample. Complete oxidation is ensured by passing the combustion products through a bed of chromium trioxide at $1000^{\circ} \mathrm{C}$. The oxidation products pass through a reduction reactor packed with elemental copper and copper oxide at $650^{\circ} \mathrm{C}$ to remove excess oxygen and reduce the nitrous oxides $\left(\mathrm{NO}_{\mathrm{x}}\right)$ to elemental nitrogen. Water is removed from the gas stream using a trap containing anhydrous magnesium perchlorate. The gases then enter a chromatographic column for separation of $\mathrm{N}_{2}$ from $\mathrm{CO}_{2}$ which are then bled into the IRMS via crimp or open split.

Gas chromatography-combustion IRMS (GC-C-IRMS) is capable of measuring isotope ratios in a compound independent manner. For example the carbon isotope ratios for individual fatty acid methyl esters (FAMEs) in a mixture may be measured using this technique. The GC effluent is directed to combustion tube for conversion to $\mathrm{CO}_{2}$ (Figure 2).

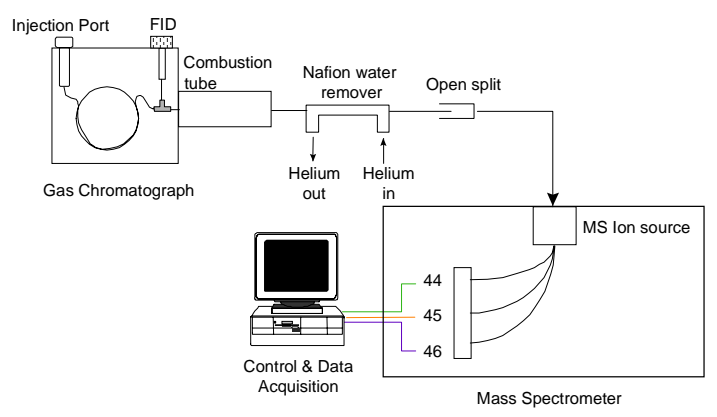

Figure 2

Schematic diagram of a gas chromatography-combustionisotope ratio mass spectrometer (GC-C-IRMS)

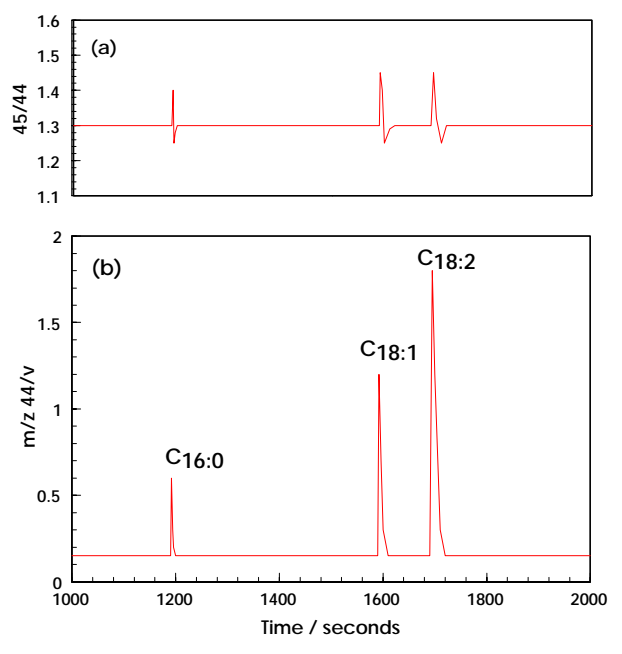

Figure 3

Output from a GC-C-IRMS instrument for the fatty acid methyl esters [palmitic $\left(C_{16: 0}\right)$ oleic $\left(C_{18: 1}\right)$ and linoleic $\left(C_{18: 2}\right)$ ] from maize oil showing (a) the instantaneous ratio of the $\mathrm{m} / \mathrm{z} 45$ to $\mathrm{m} / \mathrm{z} 44$ beams and (b) the absolute $\mathrm{m} / \mathrm{z} 44$ beam intensity.

The combustion tube is comprised of a ceramic furnace with a copper oxide and platinum catalyst maintained at $960^{\circ} \mathrm{C}$. A post column split also connects the GC eluent flow to a flame ionisation detector allowing a conventional chromatogram to be obtained. Water is removed from the combustion gases by passing them through a Nafion tube which is permeable to water but not to $\mathrm{CO}_{2}$. The water must be removed to prevent the formation of $\mathrm{HCO}_{2}{ }^{+}$, which has the same mass as ${ }^{13} \mathrm{CO}_{2}$. The gas stream is then bled into the IRMS via an open split. This technique permits $\delta{ }^{13} \mathrm{C}$ measurement on nanogram quantities of individual compounds eluting from the GC with a precision of better than $0.5 \%$. Figure 3 shows the output from a GC-C-IRMS instrument for the fatty acid methyl esters [palmitic $\left(\mathrm{C}_{16: 0}\right)$ oleic $\left(\mathrm{C}_{18: 1}\right)$ and linoleic $\left(C_{18: 2}\right)$ ] from maize oil. Trace $(a)$ is the instantaneous ratio of the $\mathrm{m} / \mathrm{z} 45$ to $\mathrm{m} / \mathrm{z} 44$ beams and trace (b) is the absolute $\mathrm{m} / \mathrm{z} 44$ beam intensity.

Many compounds of interest in vegetable oils contain highly polar function groups such as carboxylic acid groups. It is possible to analyse these compounds using high-polarity stationary phases (eg FFAP-CB) However these phases generally have maximum operating temperatures in the region of $250^{\circ} \mathrm{C}$ leading to long analysis times, broad peaks and poor resolution, especially for compounds with carbon chains in excess of $\mathrm{C}_{20}$. The use of low polarity stationary phases (e.g. methylsilicone) is also unsatisfactory because of chromatographic adsorption effects such as peak tailing and loss of sample. The commonly adopted solution is to convert polar compounds to less polar derivatives.

When the delta value of a compound is required and this compound has been derivatised prior to GC-C-IRMS analysis account must be taken of the 
contribution of derivative carbon to the measured delta value of the derivatised compound. In principle, if there is no isotope fractionation process associated with the derivatization reaction then the following mass balance equation will hold

$$
\mathrm{n}_{\mathrm{cd}} \mathrm{F}_{\mathrm{cd}}=\mathrm{n}_{\mathrm{c}} \mathrm{F}_{\mathrm{c}}+\mathrm{n}_{\mathrm{d}} \mathrm{F}_{\mathrm{d}}
$$

where $\mathrm{n}$ is the number of moles of carbon, $\mathrm{F}$ is the fractional abundance of carbon -13

$c$ is the compound of interest, $d$ is the derivative group and ${ }_{c d}$ is the derivatised compound.

$F$ is defined as

$$
F=\frac{\left[{ }^{13} C\right]}{\left[{ }^{12} C+{ }^{13} C\right]}
$$

For natural abundance measurements, $\delta^{13} \mathrm{C}$ values can be used to replace $F$, the relationship between $F$ and $\delta$ being as follows

$$
F=\frac{R}{1+R}
$$

$$
\begin{aligned}
& \text { where } R=\frac{\left[{ }^{13} \mathrm{C}\right]}{\left[{ }^{12} \mathrm{C}\right]} \\
& \delta=\frac{\left(\mathrm{R}_{\text {standard }}-1\right) \times 1000}{\mathrm{R}_{\text {sample }}}
\end{aligned}
$$

Hence equation (1) can be replaced with

$$
\mathrm{n}_{\mathrm{cd}} \text { delta }_{\mathrm{cd}}=\mathrm{n}_{\mathrm{c}} \text { delta }_{\mathrm{c}}+\mathrm{n}_{\mathrm{d}} \text { delta }_{\mathrm{d}}
$$

The analysis of medium to high boiling point organic compounds by GC-C-IRMS is associated with a thermodynamic isotope effect. This effect is often known as the "inverse" chromatographic isotope effect since the heavier isotopomer elutes earlier than the lighter isotopomer. Although the effect is small it must be taken into account in applications involving natural abundance measurements. The thermodynamic effect may be reduced by injecting samples splitless to avoid potential isotopic fractionation of lower boiling point compounds. The use of an internal standard of calibrated isotope ratio that is subjected to the same chromatographic conditions as the analytes is also highly recommended (Meier-Augenstein et al. 1996).

\subsection{Authenticity of maize oil}

Maize oil is considered to be a premium vegetable oil and there is a temptation for unscrupulous
Table II

Carbon stable-isotope ratios for maize oil and other oils

\begin{tabular}{lcc}
\hline \multicolumn{1}{c}{ Oil } & Mean $\delta{ }^{13} \mathrm{C}$ & $\begin{array}{c}\text { Range } \delta^{13} \mathrm{C} \\
(\% \%, \text { versus PDB })\end{array}$ \\
\hline Maize & -14.95 & -13.71 to -16.36 \\
Other vegetable & -28.99 & -25.38 to -32.39 \\
Cereal & -31.26 & -30.38 to -32.39 \\
Fish & -26.66 & -25.37 to -27.95 \\
Animal & -30.28 & -27.56 to -32.08 \\
\hline
\end{tabular}

producers to adulterate maize oil with cheaper oils. Determining the authenticity of maize oil with traditional methods was problematic because its fatty acid composition overlaps with that of several other vegetable oils. In addition, the concentration of sterols in maize oils is very large in comparison with that of other vegetable oils, so that the sterol composition of any blend will comprise predominantly of those from maize oil. It is possible to form blends of oils whose characteristics according to traditional analysis are very similar to those of pure maize oil. Stable carbon isotope ratio analysis can be used to overcome these difficulties. Maize is $\mathrm{a} \mathrm{C}_{4}$ plant whereas all other commercial oil-bearing plants use the $\mathrm{C}_{3}$ biosynthetic pathway. Addition of, or substitution with, oil from virtually any other source, to maize oil, would therefore give rise to a $\delta{ }^{13} \mathrm{C}$ value that was more negative than authentic maize oil (Table II).

Woodbury et al. (1995) constructed theoretical mixing curves showing the variation in $\delta{ }^{13} \mathrm{C}$ values of individual fatty acids produced by mixing maize with rapeseed oil. The prepared oil blends were saponified and methylated using boron trifluoridemethanol complex. The derivatisation method used ensured that the carbon incorporated into the fatty acids on methylation came only from one source, namely the methanol of the $\mathrm{BF}_{3}-\mathrm{MeOH}$ complex. Good agreement was found between the experimental $\delta^{13} \mathrm{C}$ values and the theoretical mixing curves. A blind trial was then conducted using oil blends containing maize oil and an adulterant $\mathrm{C}_{3}$ vegetable oil in an attempt to determine the concentration of adulterant oil. The experimentally predicted values obtained for low concentrations of adulterant oil $(<10 \% \mathrm{w} / \mathrm{w})$ were within $1 \%$ of the actual value. At higher concentrations, 15-20\% adulterant oil, the values obtained were less accurate because groundnut oil was the adulterant in the blind samples rather than rapeseed which was used for the calibration.

The authors noted that the bulk $\delta{ }^{13} \mathrm{C}$ values of maize oils from different parts of the world showed a bimodal distribution, maize oils from the Southern 
Hemisphere having $\delta^{13} \mathrm{C}$ values approximately $2 \%$ less negative than oils from the Northern Hemisphere. This difference may arise because of the uneven burning of fossil fuels or some fundamental difference between the metabolisms of plants from the different hemispheres, however further work is required in this area before any firm conclusions may be reached.

Stable carbon isotope ratio analysis is undoubtedly a powerful way to identify and thus prevent maize oil adulteration, and criteria relating to this technique may be expected to appear in the appropriate Codex standards in the future.

\section{3. ${ }^{13} \mathrm{C}$ COMPOUND-SPECIFIC ISOTOPE ANALYSIS $\left({ }^{13} \mathrm{C}\right.$ CSIA)}

Generally differences in whole oil (or bulk) carbon isotopic composition are, except in the case of corn and maize products, largely inadequate for the authentication of the majority of oils which use the Calvin or $\mathrm{C}_{3}$ photosynthetic pathway. However, the isotopic analysis of individual oil components after off-line or on-line separation has shown potential for detecting $\mathrm{C}_{3}$ oil adulteration. This approach is known as compound-specific isotope analysis or CSIA. Kelly et al. (1997) have measured the $\delta^{13} \mathrm{C}$ values of palmitic, stearic, oleic and linoleic acids in $\mathrm{C}_{3}$ vegetable oils after derivatisation to the corresponding methyl esters. To reduce the effects of growing location, climate and time of harvesting the $\delta^{13} \mathrm{C}$ value of methyl oleate was used as an isotopic reference point for the other fatty acids. Although no obvious relationship existed between the $\delta^{13} \mathrm{C}$ values of the individual fatty acids and the oil type, the $\delta^{13} \mathrm{C}$ results were subjected to canonical discrimination analysis to determine the functions that would maximise the separation between different oils. Using CDA $76 \%$ of the 43 oils were correctly identified. It was observed that the majority of sunflower oils could be separated from the other oils on the basis of a single variable, the $\delta^{13} \mathrm{C}$ value of linoleic $\left(\mathrm{C}_{18: 2}\right)$ acid.

The most widely used technique to assess the authenticity of edible oils is to measure the fatty acid composition. However it is not always possible to detect adulteration by this technique because of the natural variation in fatty acid profiles and because blends of oils with fatty acid compositions similar to the authentic oil may be prepared relatively easily. A more sophisticated approach is to determine the fatty acid composition at the 2-position of the triacylglycerol (Figure 4), since this is known to differ from the overall fatty acid composition.

In the biosynthesis of triacylglycerols acyl groups are transferred from acyl-Coenzyme $\mathrm{A}$ to glycerol-3-phosphate by two distinct enzymes specific for the 1- and 2- positions. The enzyme<smiles>[R]C(=O)OCC(COC([R3])=O)OC([R])=O</smiles>

$$
\begin{gathered}
\text { Figure } 4 \\
\text { General structure of triacylglycerols, indicating the } \\
\text { 1-, 2- and 3-positions. }
\end{gathered}
$$

involved with the transfer to the 1-position exhibits a marked specificity for saturated acyl-CoA thiolesters whereas the second enzyme shows specificity towards mono- and dienoic fatty acyl-CoA thiolesters. The final step transfers a fatty acid from acyl-CoA to the diacylglycerol and the diacylglycerol transferase responsible for the catalysis of this step has a wide fatty acid specificity. Pancreatic lipase may be used to regioselectively cleave the fatty acids in the 1- and 3- positions leaving behind the 2-monoacylglycerol. Woodbury et al. (1998) used this technique to obtain the compound-specific $\delta^{13} \mathrm{C}$ values of the fatty acids specifically at the 2-position of the triacylglycerol. The cleaved products were isolated by thin layer chromatography and methylated using boron trifluoride - methanol complex. The ${ }^{13} \mathrm{C}$ values of the resulting FAMES were measured using GC-C-IRMS. The results indicated that the $\delta^{13} \mathrm{C}$ values of the fatty acids from the 2-position were identical to the fatty acids from the other positions on the glycerol backbone, despite its metabolic significance and separate esterification system. The similarities arise because the kinetic isotope effect, which discriminates against ${ }^{13} \mathrm{C}$, is greatest when ${ }^{13} \mathrm{C}$ is incorporated in small molecules such as $\mathrm{CO}_{2}$. Once primary fixation has taken place subsequent kinetic isotope effects are small and the isotope ratios in the metabolites are almost constant. The authors concluded that measurement of $\delta^{13} \mathrm{C}$ values at the 2-position of the triacylglycerol molecule did not assist with determining the authenticity of oils. However, the $\delta^{13} \mathrm{C}$ value of the whole oil and fatty acid composition at the 2-position was useful criteria in assessing oil authenticity.

Spangenberg et al. (1998) utilized the technique of CSIA to investigate the authenticity of olive oil. Principal component analysis of the fatty acid concentrations and $\delta^{13} \mathrm{C} \%$ o data from the whole oil and palmitic and oleic acids, permitted extra virgin olive oil (EVOO) to be distinguished from the lower grades. In addition covariance analysis of the palmitic and oleic acid $\delta^{13} \mathrm{C} \%$ o data indicated admixtures of cold pressed olive oil with refined olive 
oils or other oil types. Similarly Angerosa et al. (1997) examined differences in the $\delta^{13} \mathrm{C} \%$ 。 values of the aliphatic alcoholic fraction of pomace oil. They found that $\delta^{13} \mathrm{C} \%$ ovalues of this fraction of pomace oil were significantly more negative than those of virgin and refined olive oils (Figure 5 ). With this approach they were able to detect olive oil adulteration with cheaper pomace olive oil, at concentrations of $5 \%$ in some instances. This technique proved to be more sensitive than methods currently integrated into olive oil regulations, such as wax analysis. Most recently, Royer et al. (1999) examined 188 olive oils, produced mainly in Greece during 1993 to 1996. The concentration and $\delta^{13} \mathrm{C} \%$ value of individual fatty acids present in the olive oils were determined by gas chromatography and GC-C-IRMS respectively. The results were examined in terms of geographical, temporal, and botanical factors. French and Italian olive oils were securely classified at the $99.9 \%$ confidence interval using the $\delta^{13} \mathrm{C} \%$ ovalues of the principal fatty acids palmitic $\left(\mathrm{C}_{16: 0}\right)$, oleic $\left(\mathrm{C}_{18: 1}\right)$ and linoleic $\left(\mathrm{C}_{18: 2}\right)$. Regional classifications for the Greek olive oils were also achieved on the basis of differences $(\Delta)$ in the ${ }^{13} \mathrm{C}$ abundance of oleic $(\mathrm{O})$ acid compared to linoleic $(\mathrm{L})$ acid $[\Delta(\mathrm{O}-\mathrm{L})]$ and palmitic $(\mathrm{P})$ acid $[\Delta(\mathrm{O}-\mathrm{P})]$. These parameters were also sufficiently robust to differentiate two consecutive years of production of olive oil.

Glycerol is a primary metabolite in plants. It is nominally present in its ester form as glycerolipids in fats and oils (Kiritsakis and Christie 1999). Glycerol is bio-synthesised relatively early in the lipidic metabolic pathway compared to fatty acids (Weber et al. 1997; Harwood and Sánchez 1999). Consequently, it may be expected that the isotopic distribution in glycerol is a better indicator of the botanical and environmental influences on any given plant. The isotopic analysis of glycerol has received much attention recently in

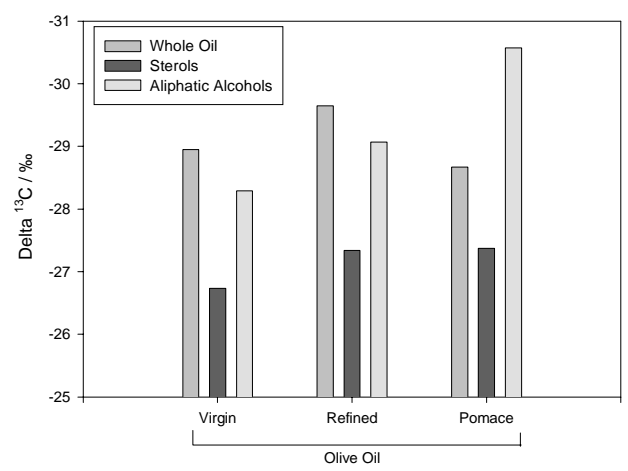

Figure 5

Bar chart showing the $\delta^{13} \mathrm{C}$ values of the whole oil and corresponding sterols and aliphatic alcohols of virgin olive oil, refined olive oil and pomace oil. Adapted from Angerosa et al (1997). attempts to detect the fraudulent practice of adding glycerol to wine to 'improve' the full-bodiedness and mouthfeel of lower quality products. Furthermore, glycerol is used in large quantities in commercial food preparations and specific groups of consumers may be particularly sensitive about the origin of animal derived products on religious grounds. Within this broader framework, a number of compoundspecific IRMS studies on glycerol have been performed, some of which include data derived from vegetable oils. Bianchi et al. (1993) studied the carbon isotope discrimination in whole oil and some of its components, including glycerol, from four Italian olive varieties different stages of maturity. The bulk or average $\delta^{13} \mathrm{C} \%$ 。 values of the whole oil ranged between -27.2 to $-28.6 \%$. The other oil components including sterols and aliphatic alcohols ranged from -25.2 to $-28.4 \%$. Notably, the glycerol $\delta^{13} \mathrm{C} \%$ o values $(-28.1$ to $-30.3 \%$ ) were significantly depleted relative to the ${ }^{13} \mathrm{C}$ abundance of the whole oil and other fractions. It was concluded that the observed ${ }^{13} \mathrm{C}$ isotopic fractionation between the oil components had implications for the purity and origin assessment of olive oils. What is perhaps more intriguing is the source of these isotopic differences and this can really only be understood by examining the emerging technique of intra-molecular IRMS analysis, which is discussed in the following section.

\section{4. ${ }^{13} \mathrm{C}$ POSITION SPECIFIC ISOTOPE ANALYSIS $\left({ }^{13} \mathrm{C}\right.$ PSIA)}

The determination of position-specific or site-specific isotope ratios has long been the domain of quantitative nuclear magnetic resonance spectroscopy (Martin and Martin 1981; Caer et al. 1991), more specifically the SNIF-NMR ${ }^{\mathrm{TM}}$ technique. Whilst, this technique is fully acknowledged as providing a practical tool for authenticity studies and a valuable insight into intra-molecular isotopic distributions, some limitations must be recognized in terms of sample quantities required, and measurement acquisition times. Position-specific isotope analysis (PSIA) measured by IRMS has been used previously in food authentication (Krueger and Krueger 1983; 1985) but has not gained wide acceptance because the technique requires time consuming off-line chemical cleavage, and recovery of molecular fragments, without introducing isotopic fractionation. Nevertheless, IRMS does offer some advantages in terms of speed of instrumental analysis and the small quantities of sample required. As such, it has provided valuable information on the isotopic distribution of ${ }^{13} \mathrm{C}$ within glycerol that can be used for plant metabolism studies, botanical source determinations and the detection of fraud. Weber et al. (1997) reported that the average $\delta^{13} \mathrm{C} \%$ o value of glycerol from a botanical origin was 4 to $5 \%$ o more negative than that of carbohydrates from the same 


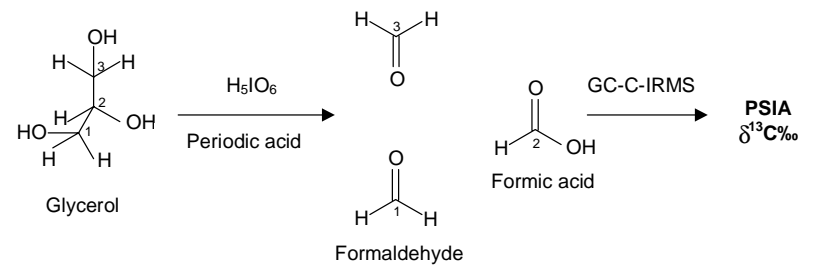

Figure 6

Schematic representation of the periodate degradation of glycerol to form formaldehyde and formic acid. The formaldehyde retains the carbon isotopic signature of the $C_{1}$ and $C_{3}$ atoms of the parent glycerol, whereas the formic acid retains the $\mathrm{C}_{2}$ information. The $\delta^{13} \mathrm{C} \%$ value of the volatile products can be determined directly by GC-Combustion-IRMS.

source. This depletion was related exclusively to a large depletion at the $\mathrm{C}_{1}$ position of the glycerol molecule. This PSIA was performed after degrading the glycerol with periodic acid. Figure 6 shows a schematic representation of the periodate degradation reaction. The stoichiometry of the reaction is such that one mole of periodic acid is required to cleave each pair of adjacent hydroxyl groups. As a result, one mole of glycerol yields two moles of formaldehyde and one mole of formic acid (Smith and Duke 1943). The formaldehyde retains the carbon isotopic signature of the $\mathrm{C}_{1}$ and $\mathrm{C}_{3}$ atoms of the parent glycerol, whereas the formic acid retains the $\mathrm{C}_{2}$ information. Weber et al. (1997) determined the $\delta^{13} \mathrm{C} \%$ ovalue of the volatile products directly by GC-Combustion-IRMS.

In addition they demonstrated that the depletion of glycerol was a compensation for small ${ }^{13} \mathrm{C}$ enrichments in the corresponding positions of hexoses formed during the metabolic fluxes of dihydroxyacetone phosphate. The numerical difference between the average $\delta^{13} \mathrm{C} \%$ and the $\mathrm{C}_{1}$ position of glycerol was reliable indicator of plant, animal and synthetic origin. Later, Zhang et al. (1999) conducted an investigation into the equivalence of ${ }^{13} \mathrm{C}$ SNIF-NMR and PSIA-IRMS measurements of glycerol derived from plant and animal sources. They compared direct measurement of ${ }^{13} \mathrm{C}$ abundance of $\mathrm{C}_{1,3}$ and $\mathrm{C}_{2}$ of glycerol by NMR (using a complex least squares curve-fitting algorithm) with position-specific isotope ratios measured by IRMS (after periodate degradation). The repeatability and reproducibility of both analytical techniques were estimated. A good agreement was found between the two isotopic data sets that confirmed the dependability of the two analytical approaches.

As mentioned above, off-line preparation of degradation products for PSIA by IRMS has hindered the use of the technique for investigating intra-molecular isotopic distributions. Another confounding factor may be the availability of a relatively straightforward synthetic transformation that yields the position specificity. However, as with the development of on-line gas preparation devices for IRMS in the early 1980s, there has been an analagous development in the late 1990s of on-line pyrolytic techniques to provide molecular fragments for position specific analysis by IRMS. Two pyrolysis techniques were investigated by Dennis et al. (1998), for providing position-specific isotopic information for vanillin. A Curie Point pyrolyser was used to fragment vanillin samples of known carbon isotopic composition. Hydroxy benzaldehyde, phenol and catechol were produced and identified by GC-MS. Their carbon isotopic ratios were measured by GC-C-IRMS. The extreme conditions required to produce this fragmentation and the presence of the cobalt Curie Point wire led to isotopic scrambling such that, under the conditions employed, the fragmentation products did not retain isotopic information which could be used for authentication purposes. A second pyrolytic technique generating carbon monoxide under continuous flow conditions for isotope ratio mass spectrometry (Py-CF-IRMS) was also used to study vanillin samples. This system generated carbon monoxide (CO) from samples in a modified elemental analyser. The $\mathrm{m} / \mathrm{z} 29: \mathrm{m} / \mathrm{z} 28$ ratio of $\mathrm{CO}$ provided an average $\delta^{13} \mathrm{C} \%$ ofrom the three specific carbon atoms bonded to oxygen at the methoxy, carbonyl and hydroxyl moieties, in the parent vanillin molecule. Comparison of carbon isotope data measured using this procedure agreed well with the known values of standard vanillin

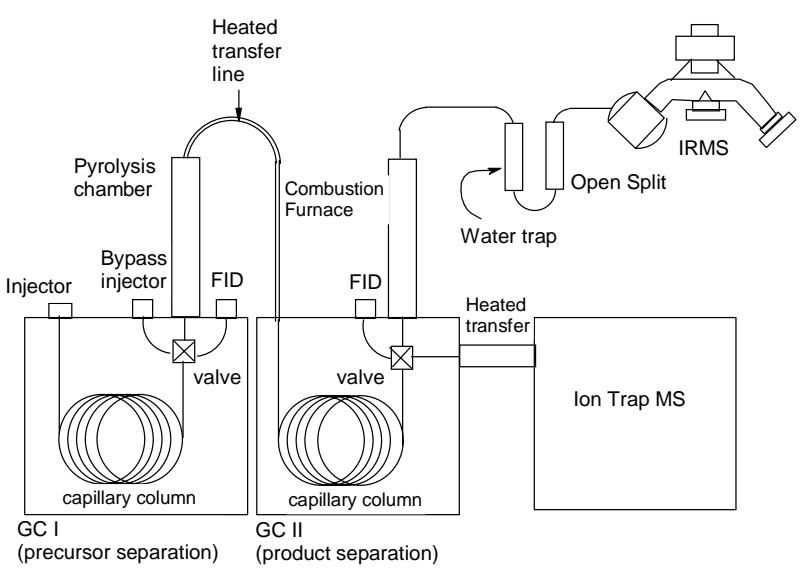

Figure 7

Schematic of instrumental system for on-line PSIA. Capillary GC-I separates the target compound from the mixture. The column effluent then passes into an empty deactivated fused silica tube $(25 \mathrm{~cm} \times 0.25 \mathrm{~mm}$ i.d. $)$ held in afurnace maintained at $550^{\circ} \mathrm{C}$. Molecular fragments pass through a heated transfer line to GC-II with the oven cooled to $-40^{\circ} \mathrm{C}$ for collection and chromatographic focusing. After separation in GC-II fragments can be directed by valving to (i) a flame ionisation detector (FID), (ii) an ion trap mass spectrometer for structural analysis, or (iii) a combustion/water trap/open-split interface to an isotope ratio mass spectrometer. (reproduced from Proc. Acad. Sci. USA (1997) 94, 1049-1053, by permission of the National Academy of Sciences, USA). 
materials. In addition the The $\mathrm{m} / \mathrm{z} 30: \mathrm{m} / \mathrm{z} 28$ ratio of $\mathrm{CO}$ provided an average ${ }^{18} \mathrm{O}$ abundance from the oxygen isotopes present in the vanillin. The oxygen isotopes provided useful information on the source discrimination of vanillin samples from fossil fuel and plant sources. Py-CF-IRMS therefore provides a rapid and convenient technique for obtaining PSIA $\delta^{13} \mathrm{C} \%$ 。 data for carbon directly attached to oxygen in organic molecules.

The feasibility of a generally applicable technique for on-line automated preparation of molecular fragments for PSIA by IRMS, was reported by Thomas Brenna's group at Cornell University (Corso and Brenna 1997). A diagram of the system they devised is shown in figure 7.

Free radical fragmentation of methyl palmitate (Me 16:0) was achieved by pyrolysis in an open tube furnace maintained at $550^{\circ} \mathrm{C}$ after separation from the hexane solvent in GC-I. They observed two series of peaks corresponding to an olefinic and methyl ester fragment breaking from each end of the parent-molecule. These were analyzed by GC-C-IRMS after cryofocusing and separation in GC-II. The repeatability of $\delta^{13} \mathrm{C} \%$ analysis of the fragments was reported as less than $0.4 \%$. In addition, Brenna and co-workers conducted a series of Isotopic labelling experiments to demonstrate the absence of rearrangement during activation and fragmentation. These data clearly demonstrated the feasibility of automated $\delta^{13} \mathrm{C} \%$ 。 PSIA for molecules contained in complex mixtures. In a subsequent publication Brenna et al explored the possibility of combining PSIA with a novel derivative of palmitic acid to establish intramolecular isotope variations. They reported the reduction of methyl palmitate to 1-hexadecanol with lithium aluminium hydride. This facilitated high-quality chromatographic separation, without adding exogenous carbon in the form of methyl derivatives (Corso et al. 1998). This is particularly useful in GC-C-IRMS as carbon added from derivatising groups cannot be differentiated from carbon in the parent compound, by chromatography-based CSIA or PSIA. After the initial GC-pyrolysis step (GC I, Figure 2), 1-hexadecanol fragmented into a series of monounsaturated alcohols and alpha-olefins analogous to the fragmentation observed for methyl palmitate, in the same system, above. In addition a pyrolytic dehydration product, 1-hexadecene was formed. The repeatability of the $\delta^{13} \mathrm{C} \%$ o GC-C-IRMS analysis (GCll, Figure 7 ) was again less than $0.4 \%$. Furthermore, their investigations showed no evidence of isotopic scrambling in the molecular fragments of 1-hexadecanol. The most recent publication by Brenna's team further increased the scope of PSIA to toluene and n-alkanes $\left(C_{5}\right.$ to $\left.C_{10}\right)$. Toluene was found to reproducibly fragment to benzene and methane and the $n$-alkanes yielded methane and $\alpha$-olefins. Furthermore the precision of the analysis was improved such that pyrolysis product isotope ratios were determined with a precision of $<0.2 \%$ and were not significantly correlated with pyrolysis temperature. Their data also demonstrated that PSIA of hydrocarbons were indicative of the source of the material (Corso and Brenna 1999). In summary the automated system developed by Brenna offers great potential for accurately and reliably determining the intramolecular distribution of isotopes in specific compounds present in complex mixtures. This is currently not offered by any other technique or system in an automated on-line configuration. Furthermore, on-line pyrolysis coupled with high-precision IRMS may provide detailed isotope information and thus a greater understanding of biosynthetic processes and is therefore likely to become a powerful weapon in the fight against economic food fraud (Corso and Brenna 1997).

\section{5. ${ }^{18} \mathrm{O}$ AND ${ }^{2} \mathrm{H}$ PYROLYSIS CF-IRMS AND POSSIBILITIES FOR BOTANICAL AND GEOGRAPHICAL ORIGIN ASSIGNMENT}

The abundance of the stable isotopes oxygen-18 $\left({ }^{18} \mathrm{O}\right)$ and deuterium $\left({ }^{2} \mathrm{H}\right)$ are particularly interesting isotopic probes for both botanical and geographical identification of a variety of different food products. Hydrogen has two stable isotopes with atomic weights $1.0079\left({ }^{1} \mathrm{H}\right)$ and $2.01\left({ }^{2} \mathrm{H}\right)$. The heavier isotope, deuterium, has a relatively low natural abundance of $150 \mathrm{ppm}$, when compared to the other bio-elements such as carbon, oxygen and nitrogen. The comparatively large difference in the mass of the isotopes of hydrogen gives rise to markedly different physical properties including rates of reaction. This means that physical processes, such as evaporation, and biological processes, involving enzyme catalysed reaction, can produce a much greater diversity of natural variation in the abundance of deuterium. Oxygen is comprised of three stable isotopes, ${ }^{16} \mathrm{O}(99.8 \%),{ }^{17} \mathrm{O}(0.04 \%)$ and ${ }^{18} \mathrm{O}(0.2 \%)$. For the purposes of IRMS studies it is the abundance of the heaviest isotope $\left({ }^{18} \mathrm{O}\right)$ that is routinely determined. The relatively smaller difference in the mass of the oxygen isotopes means that the effects of fractionating processes mentioned above do not bring about such a pronounced natural variation in ${ }^{18} \mathrm{O}$ natural abundance. The primary source of all organic hydrogen and oxygen is the hydrosphere. The meteoric water that has passed through the meteorological cycle of evaporation, condensation and precipitation finally constitutes the groundwater and exhibits a systematic geographical isotope variation. Decreasing temperatures cause a progressive heavy-isotope depletion of the precipitation when the water vapour from oceans in 
equatorial regions moves to higher latitudes and altitudes. Evaporation of water from the oceans is a fractionating process that decreases the concentration of the heavy isotopomers of water $\left({ }^{1} \mathrm{H}^{2} \mathrm{H}^{16} \mathrm{O},{ }^{1} \mathrm{H}^{1} \mathrm{H}^{18} \mathrm{O}\right)$ in the clouds compared to the sea. As the clouds move inland and gain altitude further evaporation, condensation and precipitation events occur decreasing the concentration of deuterium and oxygen-18. Consequently, the ground water reflects this isotopic gradient from the coast to inland areas. For land plants, a further pre-assimilation affects the isotopic composition of the water substrate. The hydrogen and oxygen present in plant material originates from the water taken up by the roots. The water is transported through the plants xylem system. The isotopic composition of the xylem water is the same as that of water taken in by the roots, and the water is taken into the leaves without a change in isotopic composition. Evapo-transpiration of water through the leaf stomata enriches the remaining water in the heavier isotopomers. Therefore, it is expected that growing regions with relatively low humidity, where the rate of evaporation from the leaf is higher, result in plant materials with relatively enriched $\delta^{2} \mathrm{H} \%$ and $\delta^{18} \mathrm{O}$ values. Although oxygen from carbon dioxide is initially fixed into carbohydrate during photosynthesis, this oxygen exchanges completely with leaf water prior to assimilation and therefore reflects the isotopic composition of the leaf water. Another very important factor which effects the extent of enrichment for plants growing in similar temperate climates is the surface area of leaves. This effects the rate of evapo-transpiration such that the botanical origin of agricultural products can be differentiated from plants grown in similar geographical location. The differences that exist in the hydrogen isotope composition of plant material have previously been exploited in IRMS studies to determine the botanical origin of sugars. Determination of the $\delta^{2} \mathrm{H} \%$ ratio of the nonexchangeable hydrogen atoms in sugars, after conversion to the nitro-ester derivative, has been used to authenticate wine (Dunbar and Schmidt 1984) and fruit juices (Doner et al. 1987), (Rossmann et al. 1990). Although these methods are effective they have not been widely adopted because measuring stable oxygen and hydrogen isotope ratios in organic matrices does pose certain technical problems. Off-line, dual-inlet mass spectrometry (DI-MS), methods tend to be labour-intensive, time consuming and do not readily lend themselves to high sample throughput on a routine basis. However, over the past 5 years there has been a marked increase in the use and application of ${ }^{2} \mathrm{H}$ and ${ }^{18} \mathrm{O}$ stable isotopes in many areas of food research. This has been facilitated by recent developments in on-line gas preparation devices that proceed by high temperature pyrolysis of organic products and the availability of commercial IRMS analysers capable of measuring ${ }^{2} \mathrm{H} /{ }^{1} \mathrm{H}$ ratios in the presence of a helium carrier gas. These innovations have, to a large extent, overcome the difficulties associated with offline gas preparation for DI-MS and greatly increased the applicability of this measurement. It is now possible to routinely measure ${ }^{2} \mathrm{H}$ and ${ }^{18} \mathrm{O}$ abundances in organic samples, by Pyrolysis-Continuous Flow-Isotope Ratio Mass Spectrometry (Py-CF-IRMS).

There has been a marked increase in consumer awareness all over Europe regarding the origin of the vegetable oils they purchase. There are now a great number of branded goods declaring provincial high quality characteristics and this has particularly been the case with olive oil. In order to protect these products European Protected Denomination of Origin legislation has been introduced as an additional guarantee of quality (Council Regulation (EEC) No 2081/92). However, a wide number of chemical and sensory parameters, such as fatty acids, triglycerides, unsaponifiable matter, iodine value and so on, have been combined with multivariate statistics, but they do not provide a secure classification of geographical origin to verify PDO labelling (Aparicio 1999). This is where geographical classifications based on the stable isotope ratios of oxygen and hydrogen, when combined with other multi-element data, offer the best possibility for accurately determining origin. $A$ further issue of concern regarding geographical origin, specifically, subsidy fraud, demonstrates this point. Organised crime syndicates throughout Europe have exploited the price-support structure of the European Common Agricultural Policy for financial gain. For example, butter is a product involved in what Customs Services call circular trade. In practice this means that when EU produced butter is exported to a 'third' (non-EU country) it attracts a subsidy payment, because of lower market prices prevailing outside the EU. The same consignment of butter is then re-labelled as produce of the third country before being re-imported into the EU. The significance of re-labelling the origin of the butter is that the import tax is much less than the original subsidy paid on the export. Therefore, by simply re-labelling the geographic origin of butter, a dishonest trader can make a significant financial gain. It has been estimated that this can generate an illegal profit of as much as $£ 30,000$ per consignment of butter (Globus, 2000)

One such case involved German Customs authorities (Zollfahndungsamt Karlsruhe and Zollkriminalamt Köln) as they suspected that butter being imported from Estonia (which has access to EU markets without import taxes) was in fact illegal re-importation of EU Butter. German Customs 
officials (in consultation with the European Customs Authorities, UCLAF) went to Estonia to collect milk and butter samples from all of the major dairies. Results obtained from isotopic analysis 25 imported samples, by $\mathrm{Dr}$ Roßmann and colleagues at the Technical University of Munich, revealed that 22 samples did not fit into the isotopic pattern found for authentic Estonian samples (Roßmann 2001). Based on these results and a lack of any supporting documentation that the butter had been produced in Estonia, the companies who imported the butter were fined to recover illegal subsidy claims. German Customs observed there has been no importation of butter from Estonia since 1999. Therefore, Stable isotope ratios of the light elements $(\mathrm{H}, \mathrm{C}, \mathrm{N}, \mathrm{O}$ and $\mathrm{S}$; bioelements) and the heavy element, trontium, in natural cycles, their variations due to climate and geology, the abiotic and biological fractionation of isotopes have proved sufficiently unique to provide geographical fingerprints (Roßmann et al. 2000). Whilst there is no evidence for biological fractionation of this strontium ratios $\left({ }^{88} \mathrm{Sr} /{ }^{86} \mathrm{Sr}\right)$, the study of its stable isotopes are of growing importance for verifying the geographical origin of food. Furthermore this methodology has recently proved sufficiently robust to be admissible in criminal prosecutions.

Preliminary investigations into the application of ${ }^{18} \mathrm{O}$-pyrolysis continuous-flow IRMS to obtain information about the geographical origin of olive oil samples has been conducted by Angerosa et al. (1999) They measured the $\delta^{13} \mathrm{C} \%$ and $\delta^{18} \mathrm{O} \%$ ovalues of whole olive oil, sterols and aliphatic alcohol fractions from fruits of Olea europaea L. produced in Greece, Italy, Morocco, Spain, Tunisia, and Turkey. The results permitted provincial classification of the oils. However, there was some misclassification observed for oil samples coming from neighbouring countries with similar climates.

There is growing evidence that if these provisional assessments of the geographical origin of olive oil are supplemented with heavy isotope ratios (e.g. ${ }^{88} \mathrm{Sr} /{ }^{86} \mathrm{Sr}$ ) and multi-element data, gathered by inductively coupled plasma-mass spectrometry, that a secure geographical classification of this product can be achieved. Thus ensuring that the consumer is not defrauded, and that the honest trader is not disadvantaged by having their PDO oils misrepresented by inferior products.

\section{REFERENCES}

Angerosa, F., Camera, L., Cumitini, S., Gleixner, G. \& Reniero, F. (1997). Carbon stable isotopes and olive oil adulteration with pomace oil. J. Agric. Food Chem., 45, 3044-3048.

Angerosa, F., Breas, O., Contento, S., Guillou, C., Reniero, F. \& Sada, E, (1999). J. Agric. Food Chem., 47, 1013-1017.

Aparicio, R. (1999). Characterization: Mathematical procedures for chemical analysis in Handbook of olive oil, p. 129-158. J. Harwood \& R. Aparicio (Eds.), Aspen publisher Inc., Maryland, USA.

Bianchi G, Angerosa F, Camera L, Reniero F, Anglani C. (1993) Stable carbon-isotope ratios ${ }^{13} \mathrm{C} /{ }^{12} \mathrm{C}$ of olive oil components J. Agric. Food Chem., 41,1936-1940.

Bricout, J., Koziet, J. (1987). Control of the authenticity of orange juice by isotopic analysis. J. Agric. Food Chem., 35, 758-760.

Caer, V., Trierweiler, M., Martin, G. J. \& Martin, M. L. (1991) Determination of site-specific carbon siotope ratios at natural abundance by ${ }^{13} \mathrm{C}-\mathrm{NMR}$ spectroscopy, Anal. Chem., 63, 2306-2313.

Chapman, T. E., Berger, R., Reijgoud, D. J. and Okken, A. (1990) Stable isotopes in Paediatric Nutritional and Metabolic Research, Intercept, Andover, $\mathrm{NH}$.

Corso, T. N. \& Brenna J. T. (1997). High-precision position-specific isotope analysis. Proc. Natl. Acad. Sci. USA, 94, 1049-1053.

Corso, T. N., Lewis, P. A. \& Brenna, J. T. (1998). Reduction of fatty acid methyl esters to fatty alcohols to improve volatility for isotopic analysis without extraneous carbon. Anal. Chem., 70, 3752-3756

Corso, T. N. \& Brenna J. T. (1999). On-line pyrolysis of hydrocarbons coupled to high-precision carbon isotope ratio analysis. Anal. Chim. Acta, 397, 217-224 .

Culp, R. A.; Noakes, J. E. (1990). Identification of isotopically manipulated cinnamic aldehyde and benzaldehyde. J. Agric. Food Chem., 38, 1249-1255.

Dennis, M. J., Wilson, P., Kelly, S. D. \& Parker, I. (1998). The use of pyrolytic techniques to estimate site specific isotope data of vanillin. J. Anal. App. Pyrol., 47, 95-103.

Doner, L., Ajie, H. \& Sternberg, L. (1987). Detecting sugar-beet syrups in orange juice by $\mathrm{D} / \mathrm{H}$ and ${ }^{18} \mathrm{O} /{ }^{16} \mathrm{O}$ analysis of sucrose. J. Agric. Food Chem., 35, 610-612.

Dunbar J. \& Schmidt, H-L. (1984). Measurement of the ${ }^{2} \mathrm{H} /{ }^{1} \mathrm{H}$ ratios of the carbon bound hydrogen-atoms in sugars. Fres, Z. Anal. Chem., 317, 853-857.

Ehleringer, J. R., Rundel, P. W. (1988) In Stable Isotopes: History, units and instrumentation, Rundel, P. W., Ehleringer, J. R. and Nagy, K. A. Eds., Springer-Verlag, New York, pp $1-15$.

Firestone, D. \& Reina, R.J. 'Authenticity of vegetable oils', in Food Authentification' Editors Ashurst, P. R. and Dennis, M. J., Blackie Academic and Professional, 1996 198-258.

Globus. (2000). Translation of German TV Broadcast from Das Erste, ARD TV

Harwood, J. \& Sánchez, J. (1999). Lipid biosynthesis in olives in Handbook of olive oil, p. 129-158. J. Harwood \& R. Aparicio (Eds.), Aspen publisher Inc., Maryland, USA.

Goodacre, R., Kell, D.B. \& Bianchi, G. Rapid assessment of the adulteration of virgin olive oils by other seed oils using pyrolysis mass spectrometry and artificial neural networks. J. Sci. Food Agric., 1993, 63, 297-307.

Kelly, S. D., Parker, I., Sharman, M. and Dennis, M. J. (1997) Assessing the authenticity of single seed vegetable oils using fatty acid stable carbon isotope ratios $\left({ }^{13} \mathrm{C} /{ }^{12} \mathrm{C}\right)$, Food Chemistry, 2, 181-186.

Kiritsakis, A. \& Christie, W. W. (1999). Analysis of edible oils in Handbook of olive oil, p. 129-158. J. Harwood \& R. Aparicio (Eds.), Aspen publisher Inc., Maryland, USA

Krueger, D. A. \& Krueger, H. W. (1983). Carbon Isotopes In vanillin and the detection of falsified natural vanillin. $J$. Agric. Food Chem., 31, 1265-1268.

Krueger, D. A. \& Krueger, H. W. (1985). Detection of fraudulent vanillin labeled with ${ }^{13} \mathrm{C}$ in the carbonyl carbon, J. Agric. Food Chem., 33, 323-325. 
Martin, G. J. \& Martin, M. L. (1981). Deuterium labelling at the natural abundance level as studied by high field quantitative ${ }^{2} \mathrm{H}-\mathrm{NMR}$. Tetra. Lett., 22, 3525-3528.

Meier-Augenstein, W., Watt, P. W., \& Langhams, C-D. (1996) Influence of gas chromatographic parameters on measurement of ${ }^{13} \mathrm{C} /{ }^{12} \mathrm{C}$ isotope ratios by gas-liquid chromatography-combustion isotope ratio mass spectrometry. J. Chromatography, 752, 233-241.

O'Leary MH (1981). Carbon siotope fractionation in plants, Phytochemistry, 20, 553-567.

Parker, I G., Kelly, S.D., Sharman, M., Dennis M.J., \& Howie D. (1998) Investigation into the use of Stable Carbon Isotope Ratios $\left({ }^{13} \mathrm{C} /{ }^{12} \mathrm{C}\right)$ of Scotch Whisky Congeners to establish Brand Authenticity. Food Chem., 63, 423-428.

Rossmann, A., Rieth, W. \& Schmidt, H-L. (1990). Possibilities and results of the combination of hydrogen and carbon stable isotope ratio determination with results of conventional analyses (RSK-values) for the proof of sugar addition to fruit juices. Z. Lebensm. Unters. For., 191, 259-264.

Rossmann, A., Haberhauer, G., Holzl, S., Horn, P., Pichlmayer, F. \& Voerkelius, S. (2000). The potential of multielement stable isotope analysis for regional origin assignment of butter. Eur. Food Res. Technol., 211, 32-40.

Roßmann, A. (2001). Private communication from Dr Andreas Roßmann Technical University of Munich, FRG.

Royer, A., Gerard, C., Naulet, N., Lees, M. \& Martin G. J. (1999) Stable isotope characterization of olive oils. I -
Compositional and carbon-13 profiles of fatty acids. J. A. O. C. S., 76, 357-363.

Smith, G. \& Duke, F. (1943). Cerate and periodate oxidimetry: perchlorato-cerate and periodate ions as oxidants in the determination of organic compounds. Ind. Eng. Chem., Anal. Ed., 15, 120-122.

Spangenberg, J. E., Macko, S. A. \& Hunziker, J. (1998). Characterization of olive oil by carbon isotope analysis of individual fatty acids: Implications for authentication. J. Agric. Food Chem., 46, 4179-4184.

Weber, D., Kexel, H. \& Schmidt, H-L. (1997). ${ }^{13 C}$-pattern of natural glycerol: Origin and practical importance. J. Agric. Food Chem., 45, 2042-2046.

White, J.; Winters, K.; Martin, P. (1998) Stable carbon isotope ratio analysis of honey: Validation of internal standard procedure for worldwide application. JAOAC. Int., 81, 610-619.

Woodbury, S. E., Evershed, R. P., Rossell, J. B. Griffith, R. E. \& Farnell, P. (1995) Detection of vegetable oil adulteration using gas chromatography/isotope ratio mass spectrometry. Analytical Chem., 67, 2685-2690.

Woodbury, S. E., Evershed, R. P. \& Rossell, J. B. (1998) $\delta^{13} \mathrm{C}$ analyses of vegetable oil fatty acid components, determined by gas chromatography-combustionisotope ratio mass spectrometry, after saponification or regiospecific hydrolysis. J. Chromatography, 805, 249.

Zhang, B. L., Trierweiler, M., Jouitteau, C. \& Martin G. J. (1999). Consistency of NMR and mass spectrometry determinations of natural abundance site specific carbon isotope ratios. The case of glycerol. Anal. Chem., 71, 2301-2306. 